\title{
Splitting or Sharing Resources at the Process Level: An Automotive Industry Case Study
}

\author{
Dag E. Gotteberg Haartveit ${ }^{1}$, Marco Semini ${ }^{1}$, and Erlend Alfnes ${ }^{2}$ \\ ${ }^{1}$ SINTEF Technology and Society, \\ Department of Industrial Management Trondheim, Norway \\ ${ }^{2}$ Department of Production and Quality Engineering, \\ Norwegian University of Science and Technology, Trondheim, Norway \\ \{dag.haartveit, marco.semini\}@sintef.no, erlend.alfnes@ntnu.no
}

\begin{abstract}
Original equipment suppliers (OES) supplying the automotive industry are in a business characterized by fierce competition and long contracts. Fulfilling these contracts often implies producing serial parts while an automotive is in serial production and an obligation to provide spare parts after the serial phase. The first period is characterized by large volumes and production based on stable forecasts. The second period implies production for the spare parts marked and this period is characterized by sporadic orders and small volumes. Focused factories theory suggests that production of products with different market and product characteristics should be carried out in separate focus factories. This paper discusses the feasibility of focused factory theory using an OES as an illustrative case, and presents relevant questions to address in order to achieve focus at the process level.
\end{abstract}

Keywords: Focused factories, Operations strategy, Original equipment suppliers, automotive industry.

\section{Introduction}

Original equipment suppliers (OES) supplying the automotive industry are in a business characterized by fierce competition and long contracts. Contracts for supplying original equipment manufacturers (OEM) with serial parts are usually 7 years and when they run out OES's are under obligation to provide spare parts for periods up to 15 years. The first period is characterized by large volumes and production based on stable forecasts. The second period implies production for the spare parts marked and this period is characterized by sporadic orders and small volumes.

Automotive parts are normally mass produced for efficient production in large volumes. The same production system is also utilized for low volume production of spare parts. The spare parts market has the potential of being lucrative for the OES's but serving the market requires flexible production with short lead times [1]. This creates challenges for the OES's. Being able to satisfy the marked requirements of ordinary automotive parts and spare parts demands production systems for, respectively mass production and flexible production. This influences choice of machinery, 
operators and production control, and is thereby difficult to combine in one production system. On the other hand, separating the production systems entail duplicating resources and might not be cost efficient.

The purpose of the paper is to present challenges related to focused factories theory and to propose criteria and questions to address in order to achieve focus on the process level based on a comprehensive case study

The case company is a Norwegian subsidiary of a German corporation and is one of the world's largest manufacturers of car bumpers made of aluminum. It supplies bumpers to almost all mayor car manufacturers producing cars in Europe.

Since Skinner [2] introduced the concept of focused factories in 1974, creating this focus by assigning operations resources to satisfy competitive factors has been discussed by scholars. Hill [3] recently described six alternative approaches suggested within theory to find this focus. One of them were the volume approach which Semini et al. [4] applied to propose an organization of the serial and spare part production at the case company in to two different production systems and thereby suggesting two focused factories. This paper will build upon the work of Semini et al. but acknowledge Hill's finding that focus is not necessarily achieved by splitting. In some cases different resources and processes should be shared in order to reach strategic goals [3].

\section{Literature Review}

The literature review chapter will shed light on the pros and cons of applying focused factory theory. The term focused factories is limited to imply factories within factories for the remainder of this paper. This limits the scope of the term to i.e. not include decisions related to facility location.

Splitting the factory into two focused factories as was suggested by Semini et al. was thoroughly rooted in literature. Slack and Lewis [5] argues that production systems for products with clearly differing characteristics will not be effective. Porter [6] concurs by arguing that these kinds of production systems makes the company "stuck in the middle" meaning that the production system will have to cater to different, often contradictory goals with the same equipment, organization and processes. Being stuck in the middle leads to issues such as:

- Challenges in regards to choosing right levels of automation, flexibility and integration

- Challenges related to achieving flow oriented layout (product type or process type layout

- Planning and control principles not adapted to production environment or demand patterns

- Challenges related to developing knowledge and know-how for many different product types

- Challenges for the sales and marketing department handling two different markets

While the focused factory theory has been a success for many companies and industries, production of aluminum bumpers where each bumper is a serial part and then a spare part creates extraordinary issues. Production of the same product in its two 
phases requires the same product knowledge, production equipment and technological know-how etc. Production of a product with these characteristics in two focused factories seems not to be cost efficient and will according to Hyer and Wemmerlov [7] lead to these issues:

- Reduced scale effects and unnecessary duplication of tools and machinery

- Risk of sub-optimizing each factory

- Long lead times and poor utilization of capacity in marked fluctuating situations

- Loss of knowledge and know-how related to each product

- Reduced opportunity for optimized planning due to factory and resource boundaries.

The two previous sections have indicated that there is no clear cut guidance on how to split resources to ensure focus. Hill [3] suggests that the overall focus for an organization should be chosen based on the company's products' order winners and qualifiers. The next chapters will introduce the case company and propose criteria that enable organizations to find its focus by splitting or sharing at the process level.

\section{Bumper Production}

This chapter presents how bumpers are produced at the case company and goes on to explain the alternative operations strategy proposed by Semini et al.[4]

\subsection{Bumper Production at the Case Company Today}

Bumper production essentially consists of three processes. In the casting house, aluminum billets are produced from ingot, scrap metal, and alloying metals. The second process uses these billets to produce profiles of adequate shape and length by means of extrusion and cutting. More than 100 different types of profiles are produced due to unequal shapes and forms of different car models' bumpers. Finally, the third process forms the bumpers. Forming of the bumper is carried out in the bumper plant. Extruded profiles are processed in one of several automated forming lines, carrying out sawing, cutting, tempering, stretch forming, stamping, cutting and washing. Thereafter, all products need to be hardened in furnaces. While some bumpers are finished after hardening, many of them - especially spare parts - need some further processing, such as CNC (computer numerical control) machining, welding, assembly, etc. Serial parts are either sent directly to OEMs or to assembly plants where they are assembled into integrated crash management systems. Spare parts are often sent to OEM-owned central spare parts warehouses. As far as production planning and control is concerned, the forming lines operate with relatively large batches, with batch sizes varying between 2000 and 10000 bumpers.

When a serial part becomes a spare part, it is treated as before. It is often run at the same forming line as before and processed at the same $\mathrm{CNC} /$ welding machines. It is also run with the same batch sizes as before, but much more infrequently given their much lower volume. This is again due to relatively complex changeovers, which are particularly challenging for spare parts, since spare parts are produced so infrequently. Often, the tools needed to produce spare parts need considerable maintenance before 
they are ready for production again. Given that customers often order low quantities of spare parts, has led to considerable stocks of both WIP and finished spare parts, with its associated cost in the form of invested capital, space, maintenance, quality deterioration, administration and handling, and risk of obsolescence.

\subsection{Two Separated, Dedicated Factories}

The corner stone of the new operations strategy proposed by Semini et al. was to separate serial parts production from spare parts production, thereby creating two focused factories [4]. In focused factories, only products with certain characteristics are produced, which allows an increased level of focus. That is, by having separated processes, both physical and planning processes, the two factories within the factory can be run with two different focuses, each adapted to the specific needs of each product group. Products can be grouped according to volume, process, product/market, variety geography, or order-winners and qualifiers [3]; the grouping proposed by Semini et. al. [4] was done according to volume (serial parts = high volume; spare parts = low volume). The serial parts factory would produce approximately $15 \%$ of the product spectrum, which stand for approx. $80 \%$ of the volume. The spare parts factory would produce the remaining $85 \%$ of variants, standing for $20 \%$ of the volume.

\section{From Overall Focus to Focusing at the Process Level}

The question of achieving focus is not merely an overall question answered by separating production based on product volume as was introduced by Skinner [2] and proposed by Semini et. al. [4] in the previous chapter. The overall focus needs to be brought down on a process level where focus can imply both splitting and sharing individual resources, and various degrees of splitting. The following chapter will present and structure relevant questions to address in order to achieve focus on a process level, and introduce three dimensions of splitting.

\subsection{Focus at the Process Level}

While attempting to organize the production at the case company we realized that achieving focus is a stepwise but also iterative process. One need to decide on an overall focus based on the alternative approaches recapped by Hill [3]. At the same time the processes involved has to be understood and their feasibility to be split or shared for different products examined. If the process is to be split, splitting can be done to different degrees in several dimensions.

The overall focus is chosen based on analysis of the company's product and marked characteristics. Hill argues for achieving focus by focusing production to suit products with the same order winners and qualifiers. If this implies more than one focus the foci needs to be broken down on a process level. Table 1 shows the processes involved in producing aluminum bumpers at the case company. The table was developed based on the mapping guidelines presented in The extended enterprise model [8]. 
Table 1. Processes

\begin{tabular}{l|ll}
\hline Administrative processes & Physical processes & \\
\hline Order management & Inbound handling & Assembly \\
Forecasting & Internal transport & Storage \\
Production and inventory control & Production & Packaging and labeling \\
Procurement & - Casting & Outbound handling \\
Quality management & - Extrusion & External transport \\
Tooling & - Forming & \\
Performance measurement & - Machining & \\
Sales and operations planning & - Welding/CNC & \\
\hline
\end{tabular}

Each process can be split or shared to achieve the overall strategic goal each foci aims for. In order to make these decisions some questions based on six key criteria needs to be addressed. These criteria and questions are gathered and adapted from theory $[3,7,9]$ and structured in Table 2.

Table 2. Criterion and guidelines for focusing production systems with differing strategic tasks

\begin{tabular}{l|l}
\hline Criterion & Guidelines -questions to address for each process \\
\hline Competitive priority / & How do the product differences affect the particular process? \\
strategic tasks & $-\quad$ Are there differing performance objectives? \\
Complexity & $-\quad$ Are they conflicting? \\
& $-\quad$ Poes the process imply that different : \\
& $-\quad$ Technologies are used? \\
& $-\quad$ Employees work together? \\
& Is the existing complexity impeding performance? \\
Utilization & Will splitting result in lower utilization of equipment? \\
Investment & Will splitting increase overhead? \\
Competence & Does splitting imply investment requirements? Duplication of equipment? \\
& Is the same competence required for the different products? \\
Flow & Will the different foci demand specific product/process knowledge? \\
& What impact does sharing or splitting the process have on the flow between \\
& the processes (information, material, etc.)?
\end{tabular}

If the answer to the questions implies to split a process, this splitting needs to be decided for three dimensions. Should the two or more focused processes be carried out in different areas with different equipment, but at the same time be organized as one entity with employees servicing both processes? Table 3 illustrates the dimensions and span in degrees of splitting that could be chosen for each process.

Table 3. Degrees of splitting

\begin{tabular}{l|ll}
\hline Dimension & Degree of splitting & \\
\hline Spatial/Physical & Co-located - Same equipment & Geographically separated -Different equipment \\
Organizational & Integrated & Disintegrated \\
Job Specialization & Low & High \\
\hline
\end{tabular}




\subsection{Examples from the Case Company}

The overall foci for the case company were found by analyzing the company's products order winners and qualifiers as Hill proposed. The result was a serial part focus and a spare part focus. This differed from Semini et al.'s proposition by not being based on volumes. Some serial products are made in small volumes, but have the same order winners and qualifiers as other serial parts and should be produced with a serial part focus. These two foci should then be evaluated for each process in order to find if the individual process should be shared or split to which degree. The two following examples illustrate briefly these kinds of decisions. They concern two of the 22 processes identified in Table 1.

The first example is a relatively straight forward decision which regards the casting process. The cast house have large scale effects, requires large investments to duplicate and utilization of the equipment is important. The performance objectives for the casting process do not vary between the two foci and the complexity is not influenced. The process at the cast house should therefore be shared and fully integrated along the three dimensions.

The second example is the order management process. Order management at the case company is tightly connected and integrated with customer relations. Each OEM (customer) has its dedicated Key Customer Manager (KCM) which handles contracts and orders from the specific customer. The situation today is that KCM's has the responsibility for both serial and spare parts. KCM's significantly affects operations by influencing order sizes, lead times and end of life production negotiations. The performance objectives in regards to these vary significantly for serial and spare parts. The fundamentals of achieving good spare part production performance are different from serial part production. This knowledge is limited at the case company today and the knowledge that exists is not communicated to KCM's. In regards to utilization of the KCM resources, having more that one KCM per customer is excessive. These KCM's are senior employees with unique relations and knowledge of the customers that is hard and costly to duplicate. Thus, the order management process should be shared, co-located, integrated, but bolstered with employees that can support the KCM's with reaching performance objectives for spare parts. In this regard job specialization should increase in the extended order management process.

\section{Conclusion}

This paper builds on the work by Semini et al.[4], but acknowledge that the authors did not address the question of focused versus shared resources sufficiently. The characteristics of aluminum bumper production imply that some resources and processes should be shared. At the same time it is necessary to split other resources and processes in order to achieve focus. Thus, taking focusing decisions on an overall level is not sufficient. The main contribution of this paper is a presentation of relevant questions to address in order to achieve focus on a process level. The paper introduces three dimensions for which splitting decisions has to be made and briefly explains two focusing suggestions for the case company. A more thorough and complete mapping 
and evaluation of all processes and resources associated with the production of a bumper at the case company is currently being carried out in order to decide the organization of operations.

Based on the notion that some resources and processes should be shared, opportunities for further research emerge: how should the shared resources be planned and controlled? What kind of principles should be utilized to ensure that the focused parts of the factory get the level of service it should?

Acknowledgements. This research was made possible by AUTOPART (AUTOPART - World class, focused spare part production) and SFI NORMAN (SFI - Norwegian Manufacturing Future) supported by the Research Council of Norway.

\section{References}

1. IBM GLOBAL BUSINESS SERVICES, Performance in reserve; protecting and extending automotive spare parts profitability by managing complexity (2008)

2. Skinner, W.: The focused factory. Harvard Business Review 52(3), 113-121 (1974)

3. Hill, A.: How to organise operations: Focusing or splitting? International Journal of Production Economics 112(2), 646-654 (2008)

4. Semini, M., Powell, D., Alfnes, E.: Effective Service Parts Production: A Case Study. In: Proceedings of APMS 2011. Stavanger - University of Stavanger, Norway (2011)

5. Slack, N., Lewis, M.: Operations Strategy, 2nd edn. Pearson Education, Harlow (2008)

6. Porter, M.E.: What is strategy? Published (November 1996)

7. Hyer, N.L., Wemmerlöv, U.: Reorganizing the factory: Competing through cellular manufacturing. Productivity Pr. (2002)

8. Bolseth, S.: The Extent Enterprise Operations Model Toolset. Norwegian University of Science and Technology (2011)

9. Hallgren, M., Olhager, J.: Differentiating manufacturing focus. International Journal of Production Research 44(18-19), 3863-3878 (2006) 